Bei Bestimmung der Magnesia ist dieses Wiederauflösen ebenfalls, aber nicht so dringend nöthig. Denn durch überschüssiges phosphorsaures Natron gefällte und vollkommen ausgewaschene phosphorsaure Ammoniak-Talkerde liefert, wenn sie in Salzsäure nochmals gelöst und durch Ammoniak wieder gefällt wịd, ein Filtrat, das sowohl durch Magnesiamixtur, als durch phosphorsaures Natron gefällt wird. Aber der Niederschlag, welcher durch ersteres Reagens erzeugt wird, bildet sich etwas schneller und erscheint etwas, aber nur sehr unbedeutend, stärker.

Dass ein, wenn auch nur geringer, Ueberschuss der Fällungsmittel nothwendig ist, um die Fällung zu vollenden, scheint, eine häufige Erscheinung zu sein. Wenigstens habe ich mich daron überzengt, dass das Filtrat, welches erhalten wird, wenn man chemisch reinen oxalsauren Kalk in Salzsäure löst, die Lösung mittelst Ammoniaks wieder niederschlägt und den Niederschlag nach 24 Stunden von der Flüssigkeit trennt, sowohl mit oxalsaurem Kali als mit Chlorcalcium versetzt einen freilich nur sehr geringen in Essigsäure nicht löslichen Niederschlag gibt, während der unvermischt gebliebene Theil desselben vollkommen klar bleibt.

Halle, den 1. December 1869.

\title{
Ueber die Anwendung des Glycerin-Kupferoxyd-Natrons zur Nachweisung und Bestimmung des Traubenzuckers. Von
}

\section{Julius Löwe.}

Das Glycerin besitzt die Eigenschaft bei Gegenwart von Kali oder Natronlauge eine bedeutende Menge von Kupferoxydhydrat aufzulösen, und hierin liegt wohl der Grund, warum eine mit nur wenig Glycerin-versetzte wässerige lösung *irgend eines verdünnten Kupferoxydsalzes mit überschüssigem Aetzkali oder Natron keine Ausscheidung von Kupferoxydhydrat gibt, sondern alles Kupferoxyd unter tieferer Bläuung der Flï̌sigkeit in Lösung bleibt (Lassaigne). Diese Auflösung von GlycerinKupferoxyd-Natron zeigt das Verhalten des weinsauren Kupferoxyd-Natrons und lässt sich deshalb zu demselben Zwecke verwenden, ja, ihr kommen 
noch die Vorzüge zu: sich in grösserer Menge schneller bereiten zu lassen, nicht zur Schimmelbildung zu neigen und überhaupt, so weit die Erfahrungen bis jetzt reichen, eine grössere Beständigkeit selbst gegen das zerstreute Tageslicht zu besitzen. Thre Bereitung geschieht auf nachstehende Art: 16 Grm. reinen Kupfervitriol löst man in 64 Grm. Wasser und gibt zu dieser Lösung nach und nach unter Vermeidung von Wärme 80 CC. Natron-Lauge von 1,34 spec. Gew., nahe $112 \mathrm{Grm}$, darauf fügt man unter Umschütteln 6-8 Grm. reines offic. Glycerin hinzu, bis vollständige Lösung erfolgt ist, welchen Moment man leicht an der Klarheit der tieflasurblauen Flüssigkeit erkennt. In Ermangelung einer Lauge von angegebener Concentration misst man sich ein bestimmtes Volumen der zu Gebote stehenden ab und fügt von dieser der reinen Kupferlösnng so lange hinzu, bis das Hydrat sich gebildet hat und die Flüssigkeit alkalische Reaction zeigt, darauf setzt man ein dem verbrauchten Volumen gleiches Vólumen freier Lauge bei und, wie oben angegeben, unter Umschütteln Glycerin bis zum Punkte der Lösung. ${ }^{*}$ ) Eine Probe der auf diese Art bereiteten Glycerin-Kupferoxyd-Natronlösung dárf sich beim Verdünnen mit wenigstens $2 / 3$ ihres Volumens destill. Wassers nicht trüben, sie darf ferner bei längerem Erhitzen unter Vermeidung des Zutritts von Kohlensäure nicht die schwächste. Ausscheidung geben, in letzterem Falle fehlt es ihr, bei Anwendung reiner Chemikalien, meist an über'schüssiger Lauge oder Glycerin, da ein Zusatz von letzterer oder von Glycerin zu einer neuen Probe diese Erscheinung aufhebt. Ferner ist zu beachten, dass man sich zur Darstellung dieser Lösung eines reinen Glycerins bedienen muss, denn sollte dasselbe mit Rübenzucker, Dextrin u. dgl. wie von verschiedenen Seiten angegeben wurde, verunreinigt sein, so ist eine theilweise Ausscheidung von Kupferoxydul beim Erhitzen oder in der Kälte nach einiger Zeit selbstverständlich und geben sich derartige Zusätze in einem käuflichen Glycerin leicht durch diese Probe zu erkennen, schneller noch, wenn man in der Glycerinprobe eine Bildung von Traubenzucker nach bekannter Art der Reaction vorausgehen lässt. Die Bereitung einer solchen Kupferlösung von bestimmtem Titer ergibt sich von selbst, nur wäre hier noch zu erwähnen die Darstellung einer Lösung frei von einem Gehalte an schwefels. Natron, welch letzteres in

") Man kann auch das Glycerin kalt mit der Kupferlösung vermischen und darauf so viel Lauge zufügen, bis völlige Lösung des durch die Natronlauge entstandenen Niederschlags erfolgt ist. 
dem Falle lästig erscheinen könnte, wenn man die Menge des Traubenzuckers aus der Gewichtsmenge des beim Erhitzen gefällten Oxyduls ermittelt, weil hier das schwefelsaure Natron schwieriger áus der Filtersubstanz zu verdrängen ist und meist ein längeres Aussüssen erforderlich macht. Zweckmässig bedient man sich dann zur Darstellung dieser Kupferlösung des frisch gefällten Kupferoxydhydrats, welches man nach früheren Mittheilungen von mir sehr rein und von constanter Zusammensetzung erhält $(\mathrm{CuO}, \mathrm{HO})$ wenn man reinen feingeriebenen Kupfervitriol in Aetzammoniak löst und zu dieser Flüssigkeit nach und nach Natronlange gibt, bis dieselbe eben anfängt sich stark zu trüben, unter Ausscheidung von dichtem, lichtblauem Kupferoxydhydrat. Dieses Hydrat lässt sich wegen seiner dichten Beschaffenheit sehr leicht und vollständig mit kaltem Wasser answaschen und löst sich, bei $30^{\circ} \mathrm{C}$, oder neben Schwefelsäure getrocknet, bei Gegenwart von Glycerin sehr schnell und klar in Natronlauge. Da das Hydrat, auf angegebene Art bereitet, eine constante Zusammensetzung hat, lässt es sich eben so zweckmässig benützen zur Darstellung einer solchen Kupferoxydlösung ron einem bekannten Gehalte an Oxyd. Nachstehende Verhältnisse zu deren Bereitung habe ich erprobt gefunden. 6 Grm. Hydrat vermischt man mit $6-8 \mathrm{Grm}$. Glycerin und $50 \mathrm{CC}$. dest. Wasser und fügt $40 \mathrm{CC}$. Natronlauge von 1,34 spec. Gew. = ungefähr $56 \mathrm{Grm}$. hinzu, worauf unter Umschütteln schnelle Lösung erfolgt, und verdünnt bis auf $450 \mathrm{CC}$. je nach Wunsch und Bedürfniss. Dieser Lösung gebe ich entschieden den Vorzug, da sie sich in verschiedener Concentration bereiten und aufbewahren lässt, ohne dass ein Austrystallisiren von schwefels. Natron stattfindet; sie lässt sich selbst ohne Trübung mit Weingeist misehen. Nur das Kupferoxydhydrat zeigt unter angegebenen Verhältnissen grosse Löslichkeit, das wasserfreie Oxyd verhält sich gegen Glycerin bei Gegenwart von Lauge völlig indifferent.

Die Kupferlösung aus dem schwefelsauren Kupferoxyd, sowie diejenige aus dem reinen Oxydhydrat bereitet, ertragen keine sehr grosse Verdünnung, sie trüben sich in diesem Falle, in der Kälte unter Ausscheidung von Oxydhydrat, in der Siedhitze unter Ausscheidung von brannem Oxyde. Für die Bereitung sehr verdünnter Lösungen von Oxyd muss man die angegebenen Gewichtsmengen von Lange und Glycerin wenigstens verdoppein. 